University of South Florida

DIGITAL COMMONS

Digital Commons @ University of

@ UNIVERSITY OF SOUTH FLORIDA

South Florida

8-2008

\title{
Sexual Diversity, Social Inclusion and Hiv/Aids.
}

\author{
Carlos F. Cáceres \\ Cayetano Heredia University School of Public Health \\ Peter Aggleton \\ University of California \\ Jerome T. Galea \\ University of California, jeromegalea@usf.edu
}

Follow this and additional works at: https://digitalcommons.usf.edu/sok_facpub

Part of the Social Work Commons

\section{Scholar Commons Citation}

Cáceres, Carlos F.; Aggleton, Peter; and Galea, Jerome T., "Sexual Diversity, Social Inclusion and Hiv/Aids." (2008). Social Work Faculty Publications. 59.

https://digitalcommons.usf.edu/sok_facpub/59

This Article is brought to you for free and open access by the Social Work at Digital Commons @ University of South Florida. It has been accepted for inclusion in Social Work Faculty Publications by an authorized administrator of Digital Commons @ University of South Florida. For more information, please contact digitalcommons@usf.edu. 


\title{
Sexual diversity, social inclusion and HIV/AIDS
}

\author{
Carlos F. Cáceres ${ }^{a}$, Peter Aggleton ${ }^{b}$, and Jerome T. Galea ${ }^{c}$ \\ aUnit of Health, Sexuality and Human Development, Cayetano Heredia University School of \\ Public Health, Lima, Peru \\ ${ }^{b}$ Thomas Coram Research Unit, Institute of Education, University of London, London, UK \\ cProgram in Global Health, David Geffen School of Medicine, University of California, Los \\ Angeles, California, USA
}

\begin{abstract}
Despite a number of programmes to prevent HIV among men who have sex with men (MSM) and, more generally, sexually diverse populations, gay and other homosexually active men continue to be at heightened risk of HIV and its consequences. This paper analyses some of the reasons for this situation and offers policy and programmatic recommendations to contribute to a solution. The social exclusion of MSM and transgender individuals is an overwhelming reality in the majority of countries worldwide. Although progress has been achieved in some countries, in most of the world the situation remains problematic. Present challenges to equality and to the realization of health, include the membership of groups or subcultures with high HIV prevalence, lower quality and coverage of services and programmes and the impact of higher-level influences such as laws, public policies, social norms and culture, which together configure an environment that is hostile to the integration and needs of certain groups. A social inclusion perspective on HIV prevention and AIDS-related care implies the adoption of strategies to understand and confront social vulnerability. Sexual exclusion intensifies the burden of HIV transmission and morbidity. As part of a comprehensive response there is an urgent need to: (i) improve our understanding of the characteristics and HIV burden among sexually diverse populations; (ii) creatively confront legal, social and cultural factors enhancing sexual exclusion; (iii) ensure the provision of broadbased and effective HIV prevention; (iv) offer adequate care and treatment; and (v) confront special challenges that characterize work with these populations in lower and middle-income countries.
\end{abstract}

\section{Keywords}

care; HIV/AIDS; men who have sex with men; prevention; sexual minorities; social exclusion; transgender

\section{Introduction}

The uneven distribution of HIV infection within and across populations became evident early in the course of the HIV epidemic. From the start of the 1990s it became clear that alongside individual risk practices, membership of certain disadvantaged groups increased the likelihood of infection. Factors such as poverty, gender, sexuality, age, ethnicity,

\section{() 2008 Wolters Kluwer Health | Lippincott Williams \& Wilkins}

Correspondence to Professor Carlos F. Cáceres, MD, PhD, Unit of Health, Sexuality and Human Development, Cayetano Heredia University School of Public Health. Av. Armendariz 445, Lima 18, Peru. ccaceres@ upch.edu.pe.

Conflicts of interest: None. 
migration, engagement in heavily stigmatized practices (e.g. sex work and injection drug use) and incarceration all affect the risk of infection and, in turn, HIV-related morbidity and mortality [1-5]. Individually or in combination, these same factors determine the extent to which an individual or group is socially included or excluded from access to information and services that can prevent infection or mitigate the impact of HIV at individual or community levels.

In most countries in the Americas, Europe, Asia and the Pacific and the Middle-East and North Africa the relatively low prevalence of HIV in the general population contrasts with the much higher prevalence in certain groups. As a result, these countries have what are usually described as concentrated epidemics [6]. One such group comprises men who have sex with men (MSM), and includes men who self-identify as gay, bisexual or the local equivalents, male-to-female transgender individuals and other men who regularly or occasionally have sex with other men. The term MSM is used to refer to individuals born male who have sex with others who are biologically male, with the understanding of the possible conflation of very distinct groups (based on sexual orientation, gender identity and participation in sexual communities, age, social class and culture) with similarly distinct needs. In cultural contexts in which marriage is a strong social expectation, a large proportion of men in all of the above groups are likely to have female sex partners and do not necessarily identify with and participate in minority sexual communities [7-9].

Despite a number of programmes carried out over the course of the years to prevent HIV among MSM and, more generally, sexual minority groups, gay and other homosexually active men continue to be at increased risk of HIV together with its associated medical and social consequences [10]. This paper analyses some of the reasons for this gap, and offers specific policy and programmatic recommendations to contribute to a solution.

\section{Sexually diverse populations in the context of HIV/AIDS}

The use of the term 'sexual diversity' rather than men who have sex with men in the title of this paper is deliberate, because it seeks both to challenge the assumption that there is a single sexual normality and to affirm the value of different forms of sexual expression. More specifically, it questions heteronormativity as a set of practices that would have us understand all forms of sexual expression through their relationship to heterosexuality and the concomitant devaluation of non-heterosexual sexualities.

Likewise, our concern for social exclusion is deliberate. Globally, homosexually active men and male-to-female transgender individuals are at heightened risk of HIV [10] and are socially marginalized in ways that contribute to their vulnerability to infection [11-13]. Among the forces that render them such are homophobic and transphobic stigma and discrimination, human rights violations and the absence of legal frameworks offering protection. Lesbians and same-sex attracted women may also be vulnerable in the context of the epidemic. As recent research from southern Africa has shown, they may be the victims of rape and sexual abuse enacted as 'punishment' for their deviation from the heterosexual norm [14-16].

An additional level of complexity relates to the distinct, only partly overlapping categories of sexual behaviour, sexual identity and gender identification, which vary significantly across cultures. Clearly, not all - and in many countries only a minority, of MSM identify as gay or homosexual or their local equivalents - and not all of those who so identify are exclusively homosexually active. Likewise, until relatively recently, male-to-female transgender individuals tended to be classified as 'MSM', until activism from within this subpopulation advocated for their independent status. 
The term men who have sex with men (or MSM), dominant in international HIV/AIDS jargon, was introduced to the world of HIV programming in recognition of the pre-eminence of behaviours rather than identities as posing specific risks, and to facilitate the globalization of programmes oriented to this population regardless of local attitudes towards homosexuality. An extensive literature [17-19] discusses the limitations of this term and advocates for the recognition of local identities and communities (where they exist) as crucial to a proper understanding of the issues and also for the development of meaningful, participatory prevention programmes. This is difficult, however, given the existence of 'diversity within diversity' but is part of the challenge to tackle.

The focus of our analysis in this paper must account, within space limitations, for the complexity of these issues. Consequently, the evidence we will discuss will be primarily focused on biological males who have sex with other biological males, regardless of their sexual and gender identities, who are disproportionately affected by HIV globally. At the same time, many of the measures to be recommended for progress will be about confronting social exclusion in relation to sexually diverse populations as a whole, bearing in mind specific contexts and cultures. Finally, some implementation measures will imply taking into account specific sexual/gender identities and communities.

\section{Sexual diversity, social exclusion and vulnerability to HIV/AIDS}

The term 'social exclusion' describes the alienation or disenfranchisement that certain individuals or groups experience within society. Although often connected to a person's social class, sex, age or race, social exclusion is broader than this, being closely linked to social recognition and legitimacy [20,21]. Those who are socially excluded are ascribed little social value; they may be marginalized economically, politically and socially, and they cannot enjoy the economic and social opportunities available to others including access to good health.

Social exclusion not only offends against human dignity but also denies people their fundamental human rights, including rights to life and liberty, citizenship, education and health among others [22]. In most of the world's societies, and despite advances in recent years, sexually diverse populations continue to be among those most marginalized, excluded and discriminated against [23]. In consequence, their vulnerability to stigma as well as a range of social and health problems, including HIV, is heightened [24,25].

In an epidemiological sense, risk can be defined as the probability of the occurrence of a health event among members of a specific population [26]. Despite this population-based definition, risk is usually interpreted as resulting from biological and behavioural correlates labelled as 'risk factors', which are seen as operating at an individual level. Likewise, HIV risk is usually seen as a function of individual and occasionally dyadic behaviours (what one does, how many times one does it, and with whom) [27].

By the early 1990s, however, it had become clear that the global epidemic was strongly structured both in its impact and effects. The late Jonathan Mann was among the first to suggest that HIV had the capacity to exploit the fault lines of an already unequal world $[28,29]$. Thereafter, the concept of social vulnerability came to the fore, highlighting the importance of structural factors such as poverty and opportunity, gender, age, ethnicity and sexuality, social relations and peer networks, and the criminalization of certain practices, in fuelling the epidemic [30]. Notions of vulnerability emphasize the importance of politics, history and culture in determining the risks individuals face and in affecting opportunities to respond [31]. 
Within the context of HIV, vulnerability depends on at least three groups of related influences [31]: (i) membership in sexual networks with higher HIV prevalence, so that the likelihood of pairing with a partner living with HIV is higher; (ii) lower quality and coverage (in total numbers and in terms of population groups covered) of services and programmes; (iii) higher-level social/environmental influences such as laws, public policies, social norms, culture (e.g. discrimination), which configure an environment hostile to the integration and needs of certain groups.

People who are socially vulnerable and excluded quickly become vulnerable to HIV. For young women and men, the links between poverty, migration and transactional sex are strong [32-34]. Moreover, in most countries, male-to-female transgender individuals encounter limited employment opportunities, with 'entertainment' and sex work being among the few viable options $[32,35,36]$. Social exclusion may also be associated with the increased use of alcohol and illicit drugs, which can be sources of vulnerability in their own right $[37,38]$.

The social exclusion of sexually diverse populations is an overwhelming reality in the majority of countries worldwide. Although progress has been seen in some countries, and an independent declaration of human rights experts and scholars signed in 2006 in Yogyakarta, Indonesia [39], clearly articulated the links between sexual rights (in relation to sexual orientation and gender identity) and human rights, in most of the world the situation remains problematic [23].

It is impossible to understand social exclusion and enhanced vulnerability of men who have sex with men, transgender people and other sexual minorities to HIV without reference to stigma and discrimination. In its classic formulation, stigma serves as a symbolic mark imposed by dominant groups on those who are different [40]. Crucially, stigma is less an object than a process that causes certain individuals and groups to be 'significantly discredited' in the eyes of others. Stigma may be both felt and enacted. When it is enacted, it frequently results in discrimination and the denial of rights [41]. When it is felt, it can result in self-segregation or shame [42].

The origins of HIV-related stigma are complex and connect to its role in reproducing broader patterns of dominance and oppression, which are themselves the expression of deeper struggles within society for power and privilege. HIV-related stigma has a crucial role to play in reproducing inequalities of gender (through the blame that is placed on women in the epidemic), of ethnicity and race (through the equating of AIDS with Africa and the tendency to blame other countries and communities), of age (through the blaming of young people by those who are older) and of sexuality (through the stress placed on minority and 'illicit' forms of sexuality as drivers of the epidemic) [43].

\section{Addressing key barriers in the response to the HIV epidemic}

Whereas recent work has pointed to major gaps in the response to the epidemic in relation to sexual diversity [44], translation into reinvigorated forms of programming has been slow or non-existent [45]. In this section, therefore, we highlight key barriers to a more effective response and propose some actions that may allow for important steps forward. In line with other papers in this issue we provide a special focus on social exclusion and human rights.

\section{The changing contexts and needs of gay-identified and other men who have sex with men}

Do we sufficiently understand the diversity existing among MSM of various identities across cultures? Are we really reaching all non-gay identified men at risk? Are we recognizing and paying attention to contexts of special vulnerability? 
Data on the prevalence of male-to-male sex are very poor in most of the developing world. There are, however, recent indications that prevalence is higher than previously thought, with last 12 months estimates of sex between men varying between 6-8\% in south Asia and 2-25\% in Latin America [46]. Importantly, in most lower-middle income countries a very substantial proportion of MSM also have sex with women, varying between 10-50\% in Latin America, between 30-60\% in south and south-east Asia and between 60-70\% in east Asia $[47,48]$.

Nevertheless, the overall quality of data remains poor and there are deficits in many studies. Some of these problems relate to the inappropriate use of language in data collection instruments. Although it might appear simple to ask a man if he 'has ever had sex with another man', research reveals an enormous diversity of meanings with respect to terms such as 'sex' and 'men'. In many parts of the world, sexual activity between men is not talked about or is referred to only indirectly, the word 'sex' being reserved to describe activities that potentially lead to reproduction [49]. Moreover, to ask about 'sex with other men' may not elicit responses that include sex with feminized men and transgender individuals (kathoey, bakla, hijra, etc.) in certain contexts. Future studies should therefore deal more sensitively with these issues.

Limitations also exist with respect to the reporting intervals used when examining the reported frequency of same-sex sexual activity (some studies focus on lifetime measures, others on shorter and more recent periods of time) or the sexual practices enquired into (some studies focus on any sexual practice, others distinguish between anal and oral sex, but only a few examine the use of protection). Sampling adequacy is also a frequent problem, because samples are most usually small and opportunistic, are only occasionally theoretically derived, and are rarely if ever representative either of the population as a whole or of selected subgroups of MSM [46].

Moreover, only a very small number of studies have been conducted in areas of the world such as sub-Saharan Africa, north Africa and the Middle East and the Caribbean, although it is encouraging to observe that this situation has started to change in recent years $[10,46,50,51]$.

\section{Recommendation 1: understand and better reach men who have sex with men}

- More and stronger data are needed if we are to follow the current advice of the Joint United Nations Programme on HIV/AIDS (UNAIDS) to 'know our epidemics' among sexually diverse communities. The focus initially should be on those parts of the world with least data. National behavioural surveys such as the Demographic and Health Surveys (DHS) should in the future ask men about sex with other men, using language that is likely to be familiar and, if relevant, inclusive of transgender individuals. In general, there is a crucial need for the development of culturally appropriate, yet standardized, data collection instruments if there are to be better estimates of the number of MSM, the frequency with which male-to-male sexual relations occur and the contexts in which male-to-male sex takes place.

Beyond this, however, there is a need to identify better strategies to reach hard-to-reach MSM, including those who are isolated, non-gay identified and usually married, with adequate, sensitive HIV prevention, treatment and care. Part of this work will require a clearer focus on contexts of special vulnerability, including prisons and other closed institutions, as well as on the clients and sexual partners of male and transgender sex workers. Another new and promising vehicle is offered by the Internet, a technology already used by men who seek sex with other men in many countries in the world, and which is already being adopted as a space where health-related information and services can be 
offered confidentially and securely. In all of this work it will be important to avoid exposing MSM and groups working with them to the risk of state and community violence.

\section{Sexuality, the law, human rights and public policy}

What is the legal status of non-heterosexual sexual acts (or those who practise them) in specific countries in the world? Are sexually diverse populations being granted full citizenship? Are they recognized as legitimate social actors within HIV policy making and programming? Is discrimination against sexually diverse populations being adequately addressed? Are public policies and programmes adequate for these populations' needs?

Regardless of how severe the social exclusion of alternative sexual communities is, action needs to be taken to improve their access to a full citizenship and establish/foster more inclusive policies and programmes. A recent World Health Organization-convened international technical consultation defined sexual health as 'a state of physical, emotional, mental and social well-being in relation to sexuality (...) not merely the absence of disease, dysfunction or infirmity'. Sexual health requires a positive and respectful approach to sexuality and sexual relationships, as well as the possibility of having pleasurable and safe sexual experiences, free of coercion, discrimination and violence [52].

For sexual health to be attained and maintained, the sexual rights of all individuals must be respected, protected and fulfilled. The same working group defined sexual rights as embracing human rights that are already recognized in national laws, international human rights documents and other consensus statements. These include, inter alia, the right of all individuals, free of coercion, discrimination and violence: to the highest attainable standard of sexual health, including access to sexual and reproductive healthcare services; to seek, receive and impart information related to sexuality; to sexuality education; to respect for bodily integrity; to choose their partner; to decide to be sexually active or not; to consensual sexual relations; and to pursue a satisfying, safe and pleasurable sexual life [52].

National legal systems and the status of sexual diversity-One of the key challenges to access to health and human rights among sexually diverse populations in general is the continued existence of unjust and irrational laws. The most difficult type of obstacle is the existence, in a number of countries, of laws criminalizing same-sex relations and sexual/gender diversity, often leading to state-sanctioned killings and violence. In these countries, adequate provision for HIV prevention, treatment and care among sexual minority populations remains unthinkable. In other cases, although there is no criminalization, protection against hate crimes or other forms of discrimination does not exist, and the risk of occurrence of such crimes hampers the implementation of HIV prevention, treatment and care for such groups. A recent police crack-down on a 'gay sex party' in Kuala Lumpur, for example, offers a sad but pertinent example of how condoms that MSM used were admitted as official evidence of deviant behaviour: 'Police found used condoms strewn all over the floor, seven tubes of lubrication jelly' [53] - a clear indication that these men were practising safer sex.

Table 1 summarizes data from a recent UNAIDS study of the legal contexts of sexual diversity in lower and middle-income countries. According to existing information, countries were classified as repressive, neutral or protective in relation to the status of sexual diversity in their national legal systems [54].

The report above also points out that the status of sexual diversity in national legal systems shows a correlation with the legal tradition [55] to which the specific country's legal system is attached, with more repressive legal systems being associated with common law and 
Islamic traditions, and more protective systems being associated with the Roman-Germanic (civil) tradition.

Societal and cultural barriers-Independently of the legal status of sexual diversity in specific countries, state practices and cultural norms may also pose a de facto barrier to the full exercise of human rights of sexual minority populations, including access to health. Such barriers may result from effective discrimination (by the state or private parties) or from self-segregation (e.g. internalized homo/transphobia). Moreover, not only are the sexual rights of non-conforming individuals at stake, the lack of protection afforded to individuals based on their sexual orientation, gender identity or sexual practice often affects most other human rights including a basic right to safety [56-58]. Not only structural but also physical violence may impact upon the experiences and life chances of sexual minorities, intensifying more general forms of morbidity and mortality. For example, in 2006 , one death was estimated to occur every four days as a result of hate crimes against sexual minorities in Peru [59].

In the aforementioned UNAIDS study [54], the human rights status of sexually diverse populations was assessed on the basis of relevant information from statutes, reports of human rights commissions and monitoring bodies (both private and multilateral), published articles, peer-reviewed journals and testimonies of affected individuals. As shown in Table 2 , for selected human rights, trends for each region were defined in one of four levels: (i) broad violations of rights; (ii) both respect and violations of rights; (iii) generally respect of rights with some shortcomings or violations; and (iv) significant progress in fulfilling rights (see end of paper).

Lack of effective citizenship among people of sexual minority status leads to complex processes of stigmatization and exclusion. At a societal level, lack of concern about the very high HIV-related morbidity and mortality among MSM may reinforce the stigmatizing perception that populations of minority sexuality are prone to sexual disease and may lead to inadequate and insufficient health policies. In some sense, the absence of explicitly protective laws may make this barrier all the more insidious. In a recent study [60], providers of mental healthcare to sexual and gender minority groups in a rural state in the USA, for example, claimed to adopt a 'neutral' therapeutic posture when working with sexual minorities. Evidence, however, revealed that 'lesbian, gay, bisexual, transgender clients had been denied services, discouraged from broaching sexuality and gender issues by providers, and secluded within residential treatment settings' and concluded essentially that official policy and official practice with sexual minorities in terms of service delivery are often incongruent [60].

The majority experience of sexually diverse populations globally is, however, one of discrimination, stigmatization, oppression and denial. Only rarely are any of these rights upheld by national governments, only rarely do representatives of groups working with MSM participate in official policymaking (including national HIV/AIDS programmes), and only occasionally do programmes for HIV prevention and AIDS care have the depth and breadth of coverage necessary to meet local needs $[44,61]$. For example, in spite of the widespread evidence of extremely high vulnerability to HIV among MSM in Latin America, suggesting their role in the regional epidemics, many countries took several years to address this population with sensible prevention strategies [62]. Rather, time and money were wasted in disproportionate prevention campaigns oriented to the general population based on misunderstandings about how the virus was being spread.

HIV-related stigma and discrimination may be overt and visible or they may be covert and hidden. They may be direct, such as when overt prohibition is directed towards a specific 
group, or they may be indirect, such as when a norm is established that excludes specific groups. They may be enacted or anticipated such as when a person likely to be discriminated against self-segregates to avoid discrimination, and they may operate at various levels: through the law (formal), through culture (everyday interactions) and through the individual in his or her specific interactions [63]. Regardless of its nature, HIV-related stigma and discrimination denies MSM and sexually diverse populations the resources and opportunities they need to protect against HIV infection.

Inadequate public policies and programmes-Regardless of legal or societal barriers to HIV-related service provision, specific obstacles may result from within health services and health planning themselves. Health programmes for HIV prevention, treatment and care usually have to deal with two sets of challenges: first, the relative invisibility of MSM, which results in a general lack of resources and ability to respond; second the overly close identification of HIV with sexual minorities, which may trigger further stigmatization, as well as rejection by lesbian, gay, bisexual, transgender groups and communities who strive to downplay the role of HIV in sexual minority politics [64]. Health services and systems designed in this context show insufficient capacity to respond to a broader array of morbidity among sexual minority populations, failing to develop full legitimacy among them.

The examples of HIV and sexually transmitted infections are striking, obvious and well documented, but diseases such as the increased risk of anal cancer among MSM [65], with an incidence up to 20 times higher than the general population [66] or the increased risk of breast cancer among lesbians $[67,68]$ may be completely invisible to healthcare systems which are not educated in these issues and are not willing to implement programmes to address them. Whereas discrimination on the grounds of sexuality has been brought to attention by HIV, this form of discrimination has many other consequences: many services ignore and fail to respond to the specific needs of gay men, lesbians and transgender individuals [69], and discrimination itself may generate new health needs (e.g. for mental health services) [70,71].

On the positive side, recent shifts in this area should also be noted, which include the increasing involvement of organizations of sexual diversity activists in international settings (e.g. in International AIDS Conferences, in the work of United Nations bodies and in human rights networks), increased formal attention to sex between persons from the same gender in scientific conferences not specifically dedicated to HIV and AIDS [72] and increased, significant funding specifically aimed at MSM to '.. support advocacy efforts aimed at increasing funding for HIV/AIDS prevention and treatment services for MSM from public and private sources and at ending the stigma, discrimination, and violence that threaten the lives of MSM and fuel the spread of HIV/AIDS' [73].

\section{Recommendation 2: promote legal reform and implement diversity education to ensure the fulfilment of human rights-In the light of the above, a clear priority} should be the elimination of existing laws criminalizing same-sex acts and relationships, and the promotion of protective and recognition measures in all countries where they are absent. This task requires the involvement of a number of advocates at both the global and local levels. First, the advancement of international discussions and the signature of multilateral agreements, although not binding in many cases, sets the ground for new standards and reinforces the local work of advocates. Progress in this direction implies the leadership and concerted efforts of international actors who play a key role in human rights advocacy in general. Simultaneously, well-focused research on law and comparative legal systems can help identify appropriate plans, in countries following specific legal traditions, to promote legislative change and judicial change. 
As described above, work with communities and sub-populations of sexually diverse populations is also needed to enhance awareness and consciousness of rights. Within this context, HIVand AIDS can be used as strategic points of departure, but a comprehensive perspective on sexual rights as a component of human rights is also needed.

A research component is also crucial here. Comprehensive efforts should be made to understand and measure the stigmatization and discrimination affecting sexually diverse populations; the status of human rights among them and the degree to which sexually diverse communities and organizations are recognized as legitimate social actors in HIV policymaking and programme development.

Finally, there is a need to develop and implement programmes and interventions to counter discrimination, through the use of cultural mobilization (e.g. actions to increase the visibility of social exclusion on the grounds of sexuality and sexual preference) and advocacy for intervention for legal changes. As part of this work, it is important to build relationships with institutions and networks focused on sexual rights, for the consolidation of shared agendas and actions, and also to develop alliances with key professional networks, including those with progressive lawyers, judges, the police, physicians and healthcare providers, for institutional change.

\section{Prevention, care and treatment: HIV/sexually transmitted infections and beyond}

Perspectives on prevention-Are present HIV prevention programmes oriented to MSM and other sexually diverse populations working? Do they adequately address the needs of all those? Are prevention strategies and approaches fine-tuned and intensified within the context of enhanced treatment access? Are strategies and approaches responsive to the needs of new generations of men? Are quality and effectiveness being monitored? How can we improve our prevention efforts?

The above questions underscore the challenges posed by the urgency to respond to the needs of diverse groups of MSM. In many cases, programmes have been developed based on the presumed characteristics and circumstances of specific groups of men and fail to take diversity into account. In some countries, the poorest have been marginalized by programmatic actions too heavily focused on educated and articulate middle-class men, whereas in others the focus has been on particular subgroups of MSM, including sex workers, leaving aside a much larger number of other men. In most cases, non-gay identified and non-community attached MSM have been completely disregarded by HIV prevention, treatment and care programmes.

The changing realities of the epidemic call for fresh and evidence-informed responses. The increased availability of antiretroviral medication and the reframing of HIV as a chronic, manageable condition may have favoured an increase in unprotected sex among some men, particularly in industrialized countries. HIV prevention programmes have not necessarily adapted to a changing context of reduced morbidity and mortality, and many fail to utilize believable and creative approaches to sustaining safer sex in what is for many men a truly different context. In countries where HIV prevention programmes for MSM are already in place, there is a pressing need for high quality monitoring and evaluation to assess quality, coverage and, ideally, effectiveness.

Recommendation 3: ensure effective prevention-Ongoing prevention programmes should be assessed for their relevance to the present context, evaluated for effectiveness, and the changes needed should be identified. Regular, effective monitoring and evaluation is important and should include concern for coverage, quality and effectiveness. 
The impact of antiretroviral treatment in various settings with regard to preventive behaviour should be assessed, and newly strengthened HIV prevention strategies for people receiving such treatment, if needed, should be identified.

The impact of evolving sexual cultures, new entertainment technologies and new meanings attached to sexuality and risk requires better understanding, and programmes should take into account these major contextual changes [74,75]. Linked to this is the need for new HIV prevention strategies to stay one step ahead of the epidemic. This includes the implementation of ways of reaching MSM with the best models from the past, the development of specific programmes for diverse populations of men with distinct needs and the introduction of new biomedical technologies (e.g. pre-exposure prophylaxis and rectal microbicides) applied consistently and at scale within the field of prevention.

Perspectives on care and treatment-Are MSM accessing HIV-related care and treatment? Are the most vulnerable men being reached? Are services effective, inclusive and welcoming? Do health systems adequately address the other health needs of MSM and other sexual minorities?

In many places, access to HIV treatment and care has been delayed for MSM and, especially, for transgender individuals, through treatment roll-out schemes that have privileged access by other groups. In other cases, again, unwelcoming health services kept many affected men away from the benefits of the new treatments [62].

The situation is even worse as relates to other health needs of these populations. According to Dean et al. [76], health problems specific to sexually diverse groups, including MSM, include sexually transmitted infections and related problems [65,66], anxiety related to body image and sense of self including peer pressure towards particular forms of physical attractiveness, depression, anxiety and suicide related to self identity, pressure to conform to dominant gender norms, family ostracism and forced migration. Beyond this, prejudice and discrimination may restrict access to health services and result in hate crimes. Internalized homophobia may lead to self-segregation, delayed health-seeking behaviour and incomplete/ inaccurate clinical records.

When discussing an ideal model of public health service provision oriented to sexually diverse populations, a typical dilemma emerges between the choice of either specialized or integrated service provision. It is unclear whether a single response can be offered to this question, rather, it may depend on specific contexts. In the long run, all public services should be sensitive to the health needs of sexual minorities, while keeping in perspective their sexual rights and their human rights in general. Public health services should be able to respond to the health problems of a diverse population that includes sexual minorities. Plastic and reconstructive surgery services should consider the needs of men under HAART who experience lipodystrophy. Medical services should also address the needs of transgender individuals who desire to feminize their bodies through hormone therapy or bodily implants. Inclusive public health services should consider options to evolve to offer equitable, quality care to all.

Recommendation 4: ensure comprehensive treatment and care-Planning for comprehensive HIV treatment and care services should ensure that the most affected groups, including sexual diversity activist organizations, are adequately involved and served. This requires working closely with such groups in the assessment and development of services, as well as in the creation of equitable and inclusive systems of provision to ensure relevance and suitability. 
It goes without saying that HIV treatment and care programmes should be adequately evaluated, both in public systems of healthcare provision and in the private sector (including non-governmental organizations). Such evaluation implies the existence of regular monitoring and evaluation of ongoing activities, and should focus on coverage, quality and effectiveness and, again, with a perspective of responsiveness to sexual minorities' needs, equity with respect to the 'general population' and equity across subgroups.

Third, obstacles for programme success, including the need to go beyond HIV to address broader issues of sexuality, sexual health and rights, should be identified and addressed. Operations research is needed to evaluate pilot programmes to reduce inequity across class, sex, age and other divisions and to implement truly comprehensive healthcare services for sexual minority communities and groups (e.g. by assessing the strengths and weaknesses of segregated versus integrated care services).

Recommendation 5: confront special challenges-Actions to tackle the exclusion that MSM and other sexual minorities face within the context of HIV should be founded in a commitment to protecting and upholding human rights. The Yogyakarta principles and similar instruments offer a framework from within which future work can take place.

In parallel, it is important to address special challenges derived from present structures of international relations and the elements of tension, inequality and injustice within these. In this context, it is important to recognize the influence of unequal economic and political resources and their implications for how we understand the epidemic. Even though they have occasionally been used in this paper, categories such as 'homosexual', 'gay' and 'men who have sex with men' do scant justice to local understandings of sex between men in the developing world. In future work, efforts must be made to understand local epidemics in more sophisticated ways. Who a man has sex with, in what ways, and with what gender identity is of fundamental importance in HIV prevention. We must ensure that epidemiological and social descriptors and categories remain up to the task.

Beyond this there are challenges to be faced in ensuring community involvement in HIVrelated research, prevention and care, impact in public policy and the imperative to resolve ethical issues. For example, special provisions are needed to protect MSM and sexual minorities in international HIV prevention trials by minimizing the potential for coercion, ensuring the accurate understanding of risks and ensuring future access to the benefits of research. Without this, negative outcomes may include effective but expensive commercial technologies that are accessible only to northern countries or which, if made available in the south, limit access to treatment or to other forms of prevention. Critically, sexuality and sexual health education focused on the needs and circumstances of minority populations have been crucial in mobilizing, albeit slowly, an agenda of sexual rights and social inclusion that will contribute to the advancement of human rights in many parts of the world.

\section{Conclusion}

In conclusion, a social inclusion perspective on HIV prevention and AIDS care implies the adoption of a broad range of strategies to understand and confront social vulnerability. Sexual exclusion intensifies the burden of HIV transmission and morbidity and must be tackled. This paper has argued the need to: (i) improve our understanding of the characteristics and HIV burden of sexually diverse populations; (ii) creatively confront legal, social and cultural factors enhancing sexual exclusion; (iii) ensure comprehensive and effective prevention services; (iv) offer adequate care and treatment; and (v) confront special challenges that characterize the present field. Most strategies here suggested imply long- 
term effort as well as strategic vision. Success requires leadership capable of ensuring reasonable consensus among key stakeholders to move forward and safeguard the future for large numbers of people whose rights have long been neglected.

\section{References}

1. Robertson JR, Bucknall AB, Welsby PD, Roberts JJ, Inglis JM, Peutherer JF, Brettle RP. Epidemic of AIDS related virus (HTLV-III/LAV) infection among intravenous drug abusers. BMJ (Clin Res Ed). 1986; 292:527-529.

2. Gentilini M, Chieze F. Socioeconomic aspects of human immunodeficiency virus (HIV) infection in developing countries [in Italian]. Bull Acad Natl Med. 1990; 174:1209-1219. discussion 12191221. [PubMed: 2094555]

3. Rietmeijer CA, Wolitski RJ, Fishbein M, Corby NH, Cohn DL. Sex hustling, injection drug use, and non-gay identification by men who have sex with men. Associations with high-risk sexual behaviors and condom use. Sex Transm Dis. 1998; 25:353-360. [PubMed: 9713915]

4. WHO urges moves to minimize AIDS in prisons. Bull Int Union Tuberc Lung Dis. 1987; 62:60. [PubMed: 3447657]

5. Short R. Prison: no bars to AIDS. Health Serv J. 1988; 98:541. [PubMed: 10287632]

6. UNAIDS/WHO. Guidelines for second generation HIV surveillance. Geneva: World Health Organization; 2000.

7. Kendall T, Herrera C, Caballero M, Campero L. HIV prevention and men who have sex with women and men in Mexico: findings from a qualitative study with HIV-positive men. Cult Health Sex. 2007; 9:459-472. [PubMed: 17687672]

8. Safren SA, Martin C, Menon S, Greer J, Solomon S, Mimiaga MJ, Mayer KH. A survey of MSM HIV prevention outreach workers in Chennai, India. AIDS Educ Prev. 2006; 18:323-332. [PubMed: 16961449]

9. Finlinson HA, Colon HM, Robles RR, Soto M. Sexual identity formation and AIDS prevention: an exploratory study of non-gay-identified Puerto Rican MSM from working class neighborhoods. AIDS Behav. 2006; 10:531-539. [PubMed: 16736111]

10. Baral S, Sifakis F, Cleghorn F, Beyrer C. Elevated risk for HIV infection among men who have sex with men in low- and middle-income countries 2000-2006: a systematic review. PLoS Med. 2007; 4:e339. [PubMed: 18052602]

11. Díaz R, Ayala G, Bein E. Sexual risk as an outcome of social oppression: data from a probability sample of Latino gay men in three U.S. cities. Cultur Divers Ethnic Minor Psychol. 2004; 10:255267. [PubMed: 15311978]

12. Wilson P, Yoshikawa H. Experiences of and responses to social discrimination among Asian and Pacific Islander gay men: their relationship to HIV risk. AIDS Educ Prev. 2004; 16:68-83. [PubMed: 15058712]

13. Crosby R, Pitts N. Caught between different worlds: how transgendered women may be "forced" into risky sex. J Sex Res. 2007; 44:43-48. [PubMed: 17599263]

14. Black Looks. [12 May 2008] A time of hurt: lesbians raped, tortured and murdered. 2007. Available from: http://www.blacklooks.org/2007/07/a_time_of_hurt_lesbians_raped_tortured_and_murdered.html

15. Mhlambiso, N. Behind the Mask. [12 May 2008] Mpumalanga lesbian rape shows increase of hate crimes in South Africa. 2008. Available from: http://www.mask.org.za/article.php?cat=southafrica\&id=1849

16. Kassiem, AE. Lesbian pupils at high risk of rape, warn NGOs in Cape Times. Capetown: Independent News and Media; 2008.

17. Young RM, Meyer IH. The trouble with "MSM" and "WSW": erasure of the sexual-minority person in public health discourse. Am J Public Health. 2005; 95:1144-1149. [PubMed: 15961753]

18. Niang CI, Tapsoba P, Weiss E, Diagne M, Niang Y, Moreau AM, et al. Its raining stones: stigma, violence and HIV vulnerability among men who have sex with men in Dakar, Senegal. Culture, Health Sexuality. 2003; 5:499-512. 
19. Malebranche DJ, Peterson JL, Fullilove RE, Stackhouse RW, et al. Race and sexual identity: perceptions about medical culture and healthcare among Black men who have sex with men. J Natl Med Assoc. 2004; 96:97-107. [PubMed: 14746359]

20. Honneth, A. The struggle for recognition: moral grammar of social conflicts. Cambridge: Polity Press; 1996.

21. Honneth, A. Disrespect: the normative foundations of critical theory. Cambridge: Polity Press; 2007.

22. Beall, J.; Piron, L-H. DFID social exclusion review. London: London School of Economics; 2005.

23. Amnesty International. Sexual minorities and the law - a world survey. London: Amnesty International; 2007.

24. Meyer, I.; Northridge, M. The health of sexual minorities: public health perspectives on lesbian, gay, bisexual and transgender populations. Berlin: Springer; 2007.

25. Barrasa A, Lorenzo JM, Saez de Vicuna LM, Saladie P, Arellano E, Larranaga G, et al. Elevated risk of HIV infection in homosexual men even after contact with the health system [in Spanish]. Enferm Clin. 2007; 17:302-308. [PubMed: 18039438]

26. Gordis, L. Epidemiology. Philadelphia: Saunders; 2004. p. 335

27. Centers for Disease Control and Prevention. [May 2008] HIV and AIDS: are you at risk?. 2007. Available from: http://www.cdc.gov/hiv/resources/brochures/pdf/at-risk.pdf

28. Mann JM, Carballo M. Social, cultural and political aspects: overview. AIDS. 1989; 3(Suppl. 1):S221-S223.

29. Tarantola D, Gruskin S, Brown TM, Fee E. Jonathan Mann: founder of the health and human rights movement. Am J Public Health. 2006; 96:1942-1943. [PubMed: 17018812]

30. UNAIDS. Expanding the global response to HIV/AIDS through focused action - reducing risk and vulnerability: definitions, rationale and pathways. Geneva: UNAIDS; 1998.

31. Aggleton PJ. Sexuality, HIV prevention, vulnerability and risk. J Psychol Hum Sexuality. 2004; 16:1-11.

32. Maganja RK, Maman S, Groues A, Mbwambo JK. Skinning the goat and pulling the load: transactional sex among youth in Dar es Salaam, Tanzania. AIDS Care. 2007; 19:974-981. [PubMed: 17851993]

33. Chatterji M, Murray N, London D, Anglewicz P. The factors influencing transactional sex among young men and women in 12 sub-Saharan African countries. Soc Biol. 2005; 52:56-72. [PubMed: 17619631]

34. Salazar X, Cáceres C, Rosasco A, Kegeles S, Maiorana A, Garate M, Coates T. Vulnerability and sexual risks: vagos and vaguitas in a low income town in Peru. Cult Health Sex. 2005; 7:375-387. [PubMed: 16864210]

35. Melendez RM, Pinto R. 'It's really a hard life': love, gender and HIV risk among male-to-female transgender persons. Cult Health Sex. 2007; 9:233-245. [PubMed: 17457728]

36. Belza MJ, Llacer A, Mora R, de la Fuente L, Castilla J, Noguer I, Canellas S. Social characteristics and risk behaviors for HIV in a group of transvestites and male transsexuals engaging in street prostitution [in Spanish]. Gac Sanit. 2000; 14:330-337. [PubMed: 11187450]

37. Samet JH, Walley AY, Bridden C. Illicit drugs, alcohol, and addiction in human immunodeficiency virus. Panminerva Med. 2007; 49:67-77. [PubMed: 17625483]

38. Kerr-Pontes LR, Gonzalez F, Kendall C, Leao EM, Tavora FR, Caminha I, et al. Prevention of HIV infection among migrant population groups in Northeast Brazil. Cad Saude Publica. 2004; 20:320-328. [PubMed: 15029335]

39. The Yogyakarta Principles: Principles on the application of international human rights law in relation to sexual orientation and gender identity. Mar. $2007 \mathrm{At}$ : www.yogyakartaprinciples.org/docs/File/Yogyakarta_Principles_EN.pdf

40. Goffman, E. Stigma: notes on the management of a spoiled identity. New York: Simon and Schuster; 1963.

41. Maluwa M, Aggleton P, Parker R. HIV/AIDS stigma, discrimination and human rights - a critical overview. Health Human Rights. 2002; 6:1-15. 
42. Malcolm A, Aggleton P, Bronfman M, Galvao J, Mane P, Verrall J. HIV-related stigmatization and discrimination: its forms and contexts. Crit Pub Health. 1998; 8:347-370.

43. Parker R, Aggleton P. HIV and AIDS-related stigma and discrimination: a conceptual framework and implications for action. Soc Sci Med. 2003; 57:13-24. [PubMed: 12753813]

44. UNAIDS. Report of a UNAIDS stakeholder consultation. Geneva: UNAIDS; 2005.

45. Rao, JVRP. Male sexual health and HIV in Asia and the Pacific International Consultation: risks and responsibilities. New Dehli, India: Sep 23. 2006 Men who have sex with men (MSM) and transgenders: the missing link in the national response.

46. Cáceres C, Konda K, Pecheny M, Chatterjee A, Lyerla R. Estimating the number of men who have sex with men in low and middle income countries. Sex Transm Infect. 2006; 82(Suppl. 3):3-9. [PubMed: 16461592]

47. Cáceres C, Konda K, Pecheny M. Review of epidemiology of male same-sex behaviour in low and middle income countries. 2005

48. Cáceres, C.; Konda, K.; Segura, E.; Lyerla, R. Epidemiology of male same-sex behaviour and associated sexual health indicators in low and middle income countries: 2003-2007 estimates. Lima/Geneva: Cayetano Heredia University/UNAIDS; 2007.

49. Aggleton, P.; Warwick, I.; Boyce, P. Young people'e same-sex relations, sexual health and wellbeing. In: Ingham, R.; Aggleton, P., editors. Promoting young people's sexual health: international perspectives. London: Routledge; 2006.

50. Geibel S, van der Elst EM, King'ola N, Luchters S, Davies A, Getambu EM, et al. 'Are you on the market?': a capture-recapture enumeration of men who sell sex to men in and around Mombasa, Kenya. AIDS. 2007; 21:1349-1354. [PubMed: 17545712]

51. Wade AS, Kane CT, Diallo PA, Diop AK, Gueye K, Mboup S, et al. HIV infection and sexually transmitted infections among men who have sex with men in Senegal. AIDS. 2005; 19:2133-2140. [PubMed: 16284463]

52. World Health Organization. [5 December 2007] Sexual health. Available from: http://www.who.int/reproductive-health/gender/sexualhealth.html\#3

53. Malaysian police say they broke up gay sex party, arrested 37 men in International Herald Tribune. France: The Associated Press; 2007.

54. Cáceres, C., et al. Review of legal frameworks and the situation of human rights related to sexual diversity in low and middle income countries. Geneva: UNAIDS; 2008. Draft report

55. Ancel, M. Utilidade e métodos do direito comparado. (Utility and Methods of Comparative Law). Porto Alegre: SAF Editor; 1980.

56. Mohan, D. Safety as a human right. 5th World Conference on Injury Prevention and Control; 8th March 2000; New Delhi, India.

57. Ortiz-Hernández L, Granados-Cosme JA. Violence against bisexuals, gays and lesbians in Mexico City. J Homosex. 2006; 50:113-140. [PubMed: 16723343]

58. Willis DG. Hate crimes against gay males: an overview. Issues Ment Health Nurs. 2004; 25:115132. [PubMed: 14726266]

59. Bracamonte, JA.; Alvarez, RC. Informe anual 2005: situación de los derechos humanos de lesbianas, gays, trans y bisexuales en el Perú. In: Allaín, JB.; Chávez, RA., editors. 2005 Annual Report: The State of Human Rights of Lesbians, Gays, Transgenders and Bisexuals in Peru. Lima: MHOL (Homosexual Movement of Lima); 2005.

60. Willging CE, Salvador M, Kano M. Brief reports: unequal treatment: mental health care for sexual and gender minority groups in a rural state. Psychiatr Serv. 2006; 57:867-870. [PubMed: 16754766]

61. UNAIDS. HIV and men who have sex with men in Asia and the Pacific. Geneva: United Nations; 2006.

62. Cáceres, C.; Pecheny, M.; Terto, V., editors. AIDS and sex between men in Latin America: vulnerabilities, strengths and proposed measures. Lima: Cayetano Heredia University/UNAIDS/ PAHO; 2003.

63. Pecheny, M. Identidades discretas. In: Arfuch, L., editor. Identidades, sujetos y subjetividades: narrativas de la diferencia. Identities, subjects and subjectivities: narratives of difference. Buenos Aires: Prometeo; 2003. 
64. Caceres, C. Beyond AIDS: the question of health in LGBT (Lesbian, Gay, Bisexual, Transgendered) Communities. In: Minayo, MCSSS.; Coimbra, CEAA., editors. Critiques and actors: Social and Human Sciences in Health in Latin America. Rio de Janeiro: Editora Fiocruz; 2005. p. 708

65. Koblin BA, Hessol NA, Zauber AG, Taylor PE, Buchbinder SP, Katz MH, Stevens CE. Increased incidence of cancer among homosexual men, New York City and San Francisco, 1978-1990. Am J Epidemiol. 1996; 144:916-923. [PubMed: 8916502]

66. Anderson JS, Vajdic C, Grulich AE. Is screening for anal cancer warranted in homosexual men? Sex Health. 2004; 1:137-140. [PubMed: 16335300]

67. Haynes, S. Breast cancer risk: comparisons of lesbians and heterosexual women. In: Bowden, DJ., editor. Cancer and cancer risks among lesbians. Seattle: Fred Hutchinson Cancer Research Center Community Liaison Program; 1995.

68. Dibble SL, Roberts SA, Nussey B. Comparing breast cancer risk between lesbians and their heterosexual sisters. Womens Health Issues. 2004; 14:60-68. [PubMed: 15120415]

69. King M, Nazareth I. The health of people classified as lesbian, gay and bisexual attending family practitioners in London: a controlled study. BMC Public Health. 2006; 6:127-139. [PubMed: 16681849]

70. Cochran SD, Mays VM. Physical health complaints among lesbians, gay men, and bisexual and homosexually experienced heterosexual individuals: results from the California Quality of Life Survey. Am J Public Health. 2007; 97:2048-2055. [PubMed: 17463371]

71. Herek GM, Gillis JR, Cogan JC. Psychological sequelae of hate-crime victimization among lesbian, gay, and bisexual adults. J Consult Clin Psychol. 1999; 67:945-951. [PubMed: 10596515]

72. Laurence J. Men who have sex with men: a new focus internationally. AIDS Reader. 2007; 17:379-380. [PubMed: 17717880]

73. amFar AIDS Research. [15 December 2007] amfAR launches MSM initiative. 2007. Available at: http://www.amfar.org/cgi-bin/iowa/news/record.html?record=218

74. Sanders TC. M4M chat rooms: individual socialization and sexual autonomy. Culture, Health Sexuality. 2008; 10:263-276.

75. Parsons JT, Bimbi DS. Intentional unprotected anal intercourse among men who have sex with men: barebacking - from behavior to identity. AIDS Behav. 2006; 11:277-287. [PubMed: 16775771]

76. Dean L, Meyer IH, Robinson K, Sell RL, Sember R, Silenzio VMB, et al. Lesbian, gay, bisexual and transgender health: findings and concerns. J Gay Lesbian Med Assn. 2000; 4:101-151. 


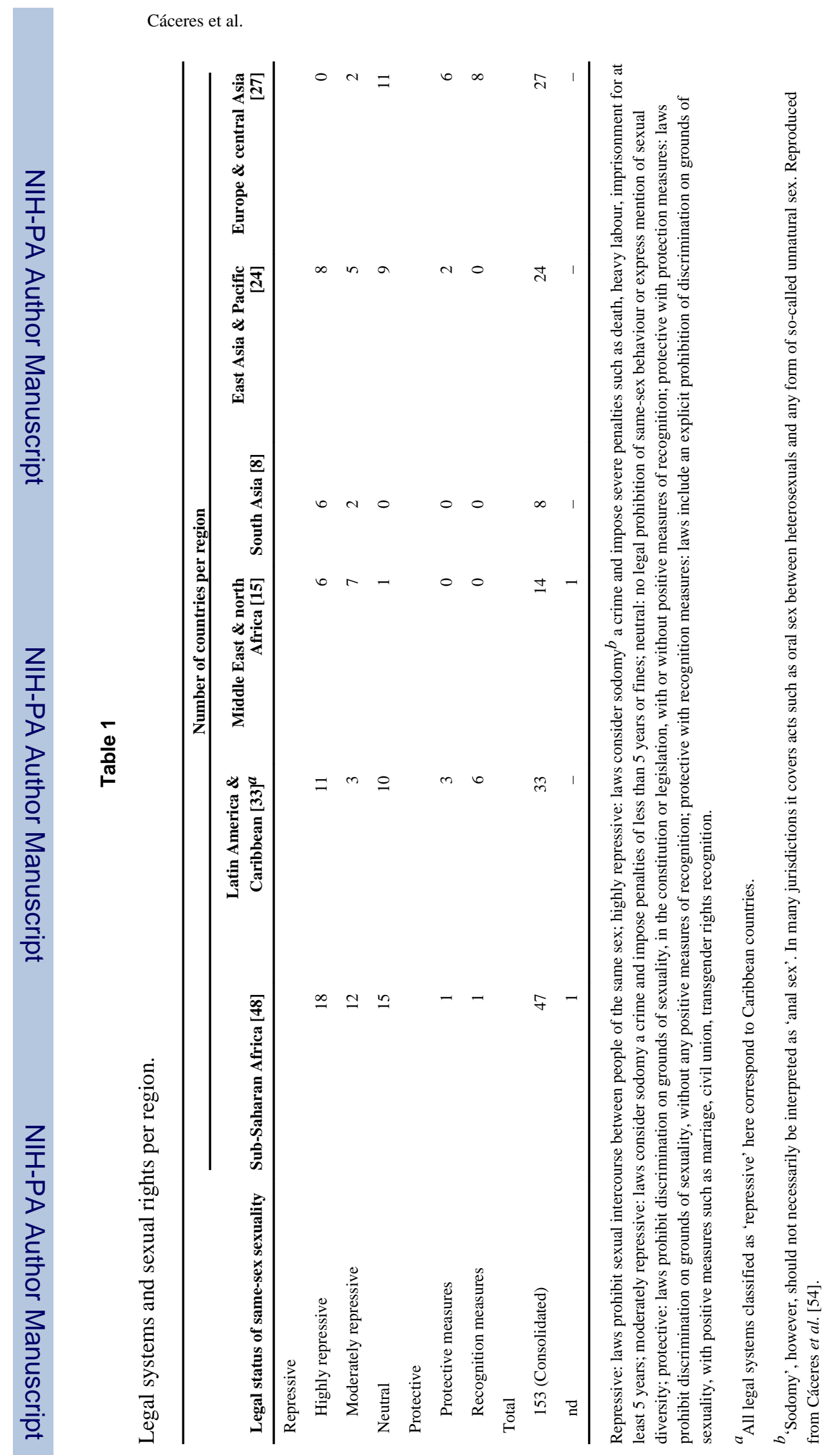

AIDS. Author manuscript; available in PMC 2012 April 19. 


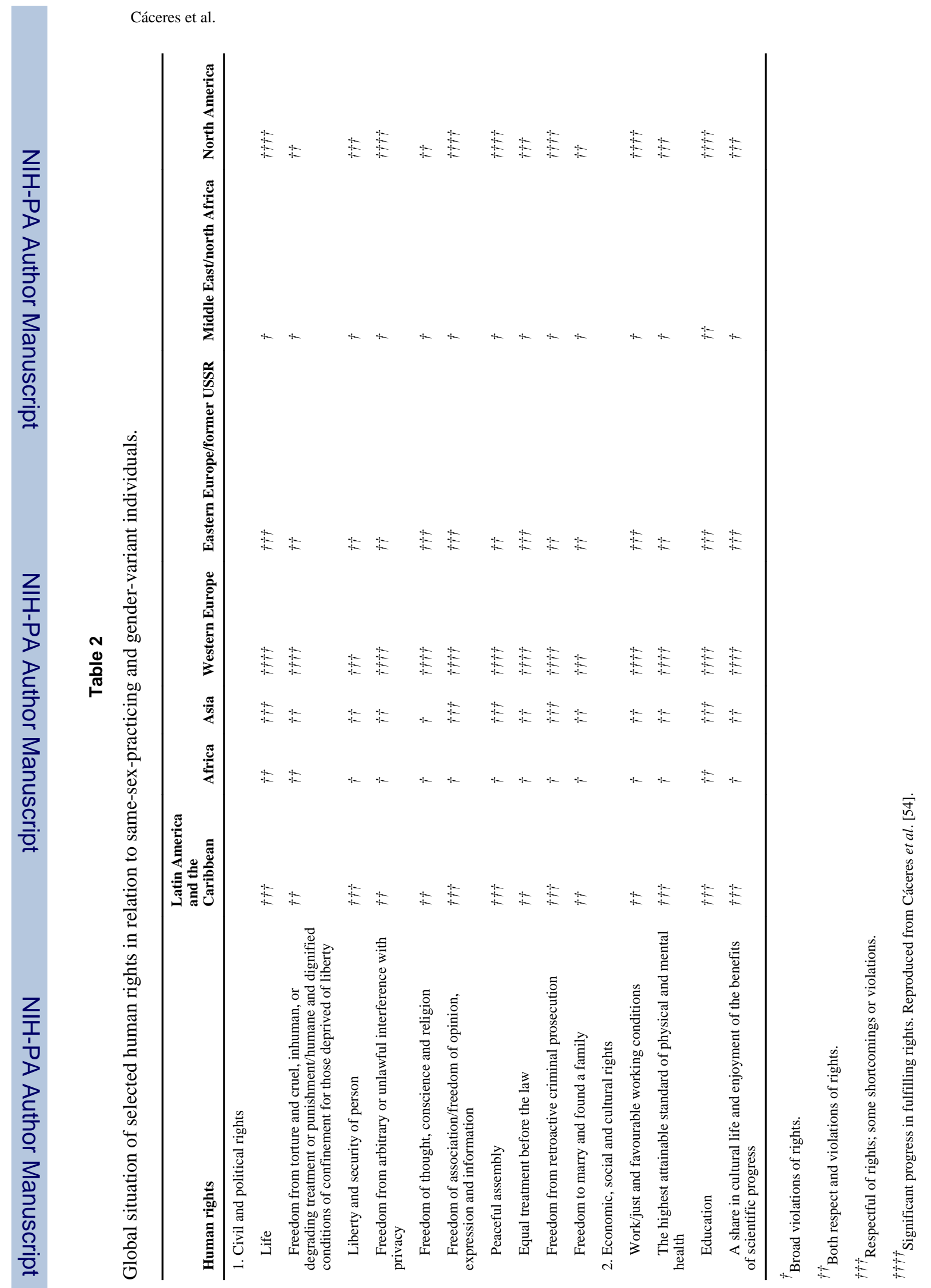

Page 17 